\title{
Accumulated X-Ray Dose Data
}

National Cancer Institute

\section{Source}

National Cancer Institute. Accumulated X-Ray Dose Data. NCI Thesaurus. Code C69230.

The total X-ray dose an individual was exposed to during a specified time period. 